\title{
KEKERASAN DALAM PACARAN (KDP) PADA REMAJA PUTRI USIA 15-18 TAHUN DI SMA MUHAMMADIYAH 4 KOTA BENGKULU
}

\author{
Gaipyana Sembiring, Sri Sumiati, Lela Hartini \\ Politeknik Kesehatan Kementerian Kesehatan Bengkulu, Jurusan Kebidanan, \\ Jalan Indragiri Nomor 03 Padang Harapan Kota Bengkulu \\ gaipyana_sma3@yahoo.com
}

\begin{abstract}
Many teens do not realize that behind the beauty of dating did not escape from the things that lead to violence is popularly called dating violence. This event looks like the iceberg phenomenon, where the case is still far greater, but many things that make it rise to the surface. The purpose of this study is to describe dating violence in adolescent girls aged 15-18 years. The study uses a descriptive research design. The results showed that $56.3 \%$ experienced emotional abuse in dating, 23.4\% experienced sexual violence in dating, $39.2 \%$ experienced physical violence in dating, $29.7 \%$ experienced economic abuse in dating and 43 $\%$ had a tendency to be a victim violence in dating. Sexual violence is a form of violence experienced by most tendency to violence in dating (30\%). The conclusion of this study is the high incidence of dating violence in adolescent girls aged 15-18 years.
\end{abstract}

Keywords : Adolescent, Dating, Dating Violence

\begin{abstract}
Abstrak: Banyak remaja tidak menyadari bahwa dibalik indahnya pacaran ternyata tidak lepas dari hal-hal yang mengarah pada kekerasan yang populer disebut kekerasan dalam pacaran. Peristiwa ini tampak seperti fenomena iceberg, kasus sebenarnya masih jauh lebih besar lagi, namun banyak hal yang membuatnya tidak muncul kepermukaan. Tujuan penelitian ini adalah untuk mengetahui gambaran kekerasan dalam pacaran pada remaja putri usia 15-18 tahun. Penelitian menggunakan rancangan penelitian deskriptif. Hasil penelitian menunjukkan bahwa 56,3\% mengalami kekerasan emosional dalam pacaran, 23,4\% mengalami kekerasan seksual dalam pacaran, 39,2\% mengalami kekerasan fisik dalam pacaran, 29,7\% mengalami kekerasan ekonomi dalam pacaran dan $43 \%$ mengalami kecenderungan menjadi korban kekerasan dalam pacaran. Kekerasan seksual adalah bentuk kekerasan yang paling banyak dialami berdasarkan kecenderungan menjadi korban kekerasan dalam pacaran (30\%). Kesimpulan dari penelitian ini adalah tingginya angka kejadian kekerasan dalam pacaran pada remaja putri usia 15-18 tahun.
\end{abstract}

Kata kunci :Remaja, pacaran, kekerasan dalam pacaran.

Masa remaja merupakan masa peralihan dari anak-anak menuju dewasa yang mencakup kematangan mental, emosional, sosial, dan fisik (Hurlock, 1999). Ketertarikan pada lawan jenis juga mulai muncul dan berkembang pada masa remaja. Rasa ketertarikan tersebut kemudian dinyatakan melalui berbagai bentuk, misalnya, berpacaran di antara mereka. Berpacaran merupakan upaya untuk mencari seorang teman dekat dan didalamnya terdapat hubungan mengkomunikasikan diri kepada pasangan, membangun kedekat- an emosional, serta proses pendewasaan kepribadian. Sekilas, hal ini terlihat cukup membahagiakan, namun unsur-unsur negatif dalam pergaulan remaja setiap saat dapat memengaruhi mereka. Salah satu faktor yang sangat rawan terjadi di kalangan remaja adalah terjadinya kekerasan dalam pacaran.

Kasus kekerasan dalam pacaran tampak berupa fenomena gunung es, kasus sebenarnya jauh lebih besar lagi, namun banyak hal yang membuatnya tidak muncul kepermukaan karena para korban tidak mence- 
ritakan kepada pihak yang berwenang mengenai masalah kekerasan yang dialami, bahkan kepada orang tuanya sendiri. Kekerasan dalam pacaran yang sebagian besar korbannya adalah perempuan ini sering diakibatkan adanya ketimpangan antara laki-laki dan perempuan yang dianut oleh masyarakat luas pada umumnya. Perempuan menurut pandangan laki-laki biasanya dianggap sebagai makhluk yang lemah, penurut, pasif, sehingga menjadi alasan utama terjadinya perlakuan yang semena-mena. Remaja lakilaki mungkin percaya: mereka memiliki hak untuk mengendalikan pasangan perempuan mereka dengan cara apapun yang diperlukan. Maskulinitas adalah agresivitas fisik, mereka memiliki pasangan mereka, mereka harus menuntut keintiman, mereka mungkin kehilangan rasa hormat jika mereka penuh perhatian dan mendukung terhadap pacar mereka, sedangkan remaja perempuan mungkin percaya: mereka bertanggung jawab untuk memecahkan masalah dalam hubungan mereka, kecemburuan pacar mereka, posesif dan bahkan kekerasan fisik, adalah romantis, pelecehan adalah normal karena teman-teman mereka juga dilecehkan, tidak ada satu pun tempat untuk meminta bantuan.

Kekerasan dalam pacaran merupakan masalah yang signifikan bukan hanya karena akan membahayakan dari segi fisik tetapi juga mental; seperti dapat mengakibatkan luka, dan rendahnya harga diri. Terlebih lagi kekerasan dalam pacaran sendiri bisa mengakibatkan kematian, dan jika terjadi pada masa remaja, maka kekerasan dalam pacaran akan mengakibatkan terganggunya hubungan romantis dan pola interaksi yang akan terbawa ke masa dewasa.

SMA Muhammadiyah 4 Kota Bengkulu merupakan sekolah menengah atas negeri yang berbasis agama Islam dan hasil survey awal di sekolah ini terdapat hanya sedikit siswi yang aktif dalam mengikuti sanggar konsultasi remaja (PIK-KRR). Tujuan penelitian adalah untuk mengetahui gambaran kekerasan dalam pacaran pada remaja putri usia 15-18 tahun di SMA Muhammadiyah 4 Kota Bengkulu Tahun 2013.

\section{BAHAN DAN CARA KERJA}

Penelitian ini merupakan penelitian deskriptif. Populasi adalah siswi yang berusia 15-18 tahun kelas X dan XI di sebuah SMA swasta berbasis keagamaan di kota Bengkulu (260 orang). Sampel diambil dengan teknik stratified random sampling dengan kriteria: merupakan siswi kelas $\mathrm{X}$ dan XI usia (15-18 tahun), mempunyai atau pernah mempunyai pacar, dan bersedia menjadi responden sebesar 158 orang.

Penelitian ini menggunakan data primer yang diperoleh langsung dari responden dengan cara mengisi kuesioner. Penelitian dilakukan selama 1 bulan mulai tanggal 21 Mei-21 Juni dan tempat penelitian di sebuah SMA swasta berbasis keagamaan di kota Bengkulu. Data dianalisis secara univariat.

\section{HASIL}

Tabel 1. Distribusi Frekuensi Kekerasan dalam Pacaran (KDP) pada Remaja Putri Usia 15-18 Tahun di SMA Muhammadiyah 4 Kota Bengkulu

\begin{tabular}{lcc}
\hline \multicolumn{1}{c}{ Variabel } & $\begin{array}{c}\text { Frekuensi } \\
(\mathbf{n = 1 5 8})\end{array}$ & $\begin{array}{c}\text { Persentase } \\
(\mathbf{\%})\end{array}$ \\
\hline KDP Emosional & & \\
Iya & 89 & 56,3 \\
Tidak & 69 & 43,7 \\
KDP Seksual & & \\
Iya & 37 & 23,4 \\
Tidak & 121 & 76,6 \\
KDP Fisik & & \\
Iya & 62 & 39,2 \\
Tidak & 96 & 60,8 \\
KDP Ekonomi & & \\
Iya & 47 & 29,7 \\
Tidak & 111 & 70,3 \\
Kecenderungan & & \\
menjadi Korban & & \\
KDP & 68 & 43 \\
Iya & 90 & 57 \\
Tidak & & \\
\hline
\end{tabular}

Hasil analisis pada tabel 1 menunjukkan bahwa dari 158 remaja putri usia 15-18 tahun sebagian besar pernah mengalami kekerasan dalam pacaran dari segi emosional $(56,3 \%)$, sebagian kecil pernah mengalami kekerasan dalam pacaran dari segi seksual $(23,4 \%)$, hampir sebagian pernah mengalami kekerasan dalam pacaran dari segi fisik $(39,2 \%)$, dan hampir sebagian 
$(29,3 \%)$ pernah mengalami kekerasan dalam pacaran segi ekonomi.

Berdasarkan gambar 1 Bentuk kekerasan dalam pacaran segi emosional yang paling banyak terjadi adalah mengin-terogasi $(11 \%)$.

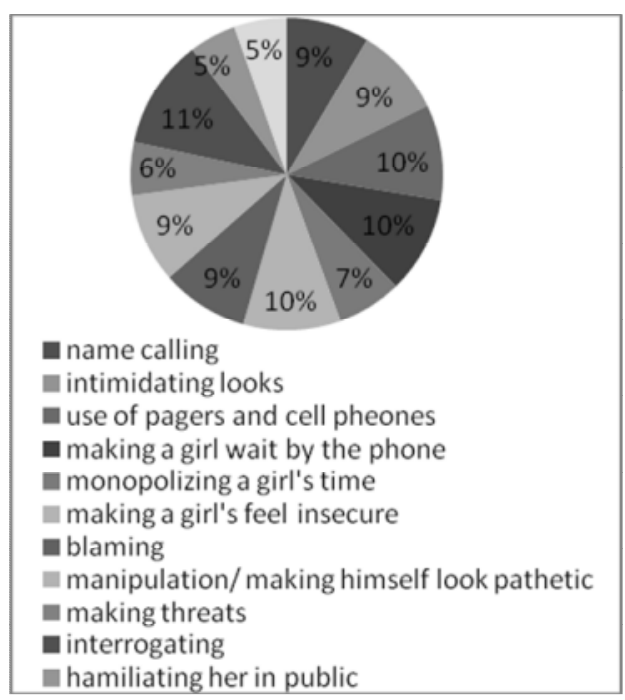

Gambar 1. Kekerasan dalam Pacaran Segi Emosional

Berdasarkan gambar 2 Bentuk kekerasan dalam pacaran segi seksual yang paling banyak terjadi adalah ciuman yang tidak diinginkan (83\%).

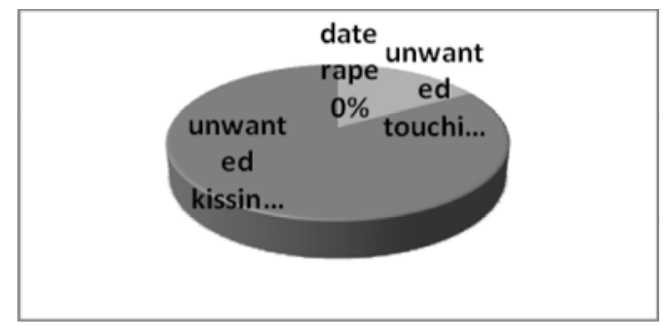

Gambar 2. Kekerasan dalam Pacaran Segi Seksual

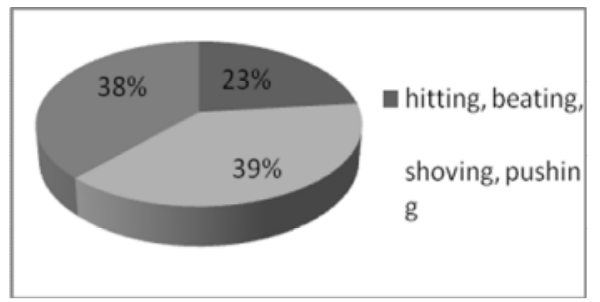

Gambar 3. Kekerasan dalam Pacaran Segi Fisik

Berdasarkan gambar 3 Bentuk kekerasan dalam pacaran segi fisik yang paling banyak terjadi adalah Menahan (39\%).
Berdasarkan gambar 4 bentuk kekerasan dalam pacaran segi ekonomi yang banyak terjadi adalah menggunakan uang dan barang pribadi tanpa pernah dikembalikan $(35 \%)$ dan meminta dibelikan barang-barang (35\%).

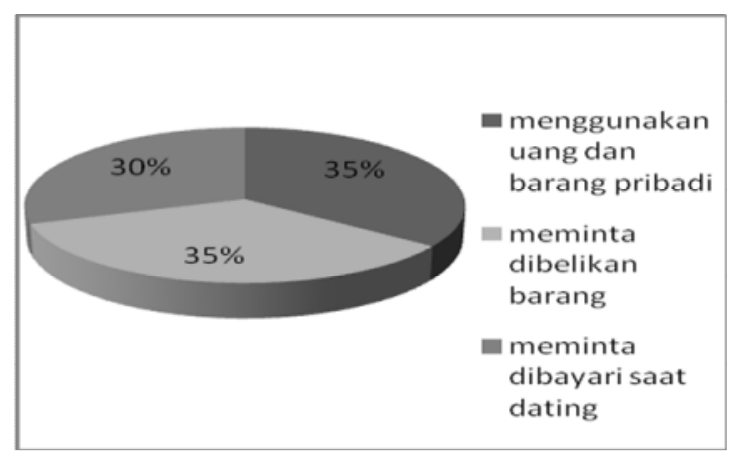

Gambar 4. Kekerasan dalam Pacaran Segi Ekonomi

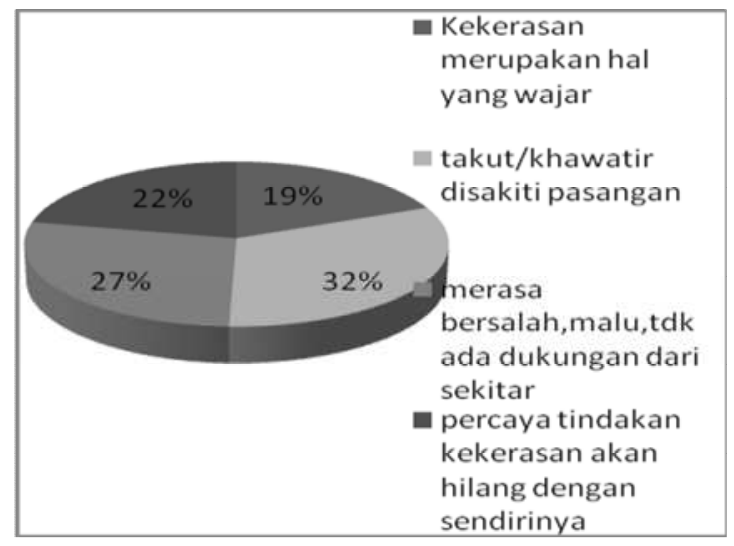

Gambar 5. Kecenderungan Remaja Putri menjadi Korban Kekerasan dalam Pacaran

Berdasarkan gambar 5 banyak remaja putri yang takut atau khawatir bahwa pacar mereka akan menyakiti atau melakukan balas dendam (32\%).

\section{PEMBAHASAN}

\section{Kekerasan Dalam Pacaran}

Berdasarkan hasil penelitian didapatkan bahwa sebagian besar responden mengalami kekerasan dalam pacaran segi emosional. Bentuk kekerasan emosional yang paling banyak terjadi adalah menginterogasi $(11 \%)$. Hal tersebut disebabkan karena mereka menganggap bentuk-bentuk kekerasan emosional merupakan tanda sayang dan keromantisan dari pacar dan perempuanlah yang bertanggung jawab menyelesaikan ma- 
salah dalam pacaran, sedangkan pria menganggap pasangan sebagai barang yang bebas diperlakukan, tindakan itu akhirnya terminifestasi dalam kekerasan dalam pacaran (The alabama Coalition Domestic Violence, 2007).

Kekerasan emosional pada remaja perempuan tidaklah dapat dibenarkan karena kekerasan terhadap perempuan adalah pelanggaran HAM. Perhatian yang terintegrasi juga dibutuhkan untuk menghentikan akibat negatif dari kekerasan dalam pacaran dengan cara mendengar suara-suara remaja yang mulai belajar untuk terbuka dan menyatakan segenap perasaannya.

Hasil penelitian menunjukan sebagian kecil responden pernah mengalami kekerasan dalam pacaran segi seksual. Bentuk kekerasan dalam pacaran segi seksual yang paling banyak terjadi adalah ciuman yang tidak diinginkan. Aktivitas pacaran pelajar sekarang ini cenderung pada tingkat yang lebih jauh. Remaja yang sedang mengalami kematangan seksual, punya rasa ingin tahu yang besar, kurangnya pemantauan orang tua, sedikitnya informasi tentang kekerasan dalam pacaran, alasan karena cinta, sayang dan alasan-alasan lainnya dapat membuat korban tidak mempermasalahkan terjadinya kekerasan seksual.

Hak-hak seksual menurut IPPF (International Planned Parenthood Federation) menjamin hak-hak Seksual bagi semua orang, termasuk kewajiban untuk menghormati, melindungi dan memenuhi hak-hak seksual, dan komitmen terhadap kebebasan dan perlindungan dari bahaya. Berdasarkan prinsip ini tidak dibenarkan adanya kekerasan seksual pada perempuan.

Berdasarkan penelitian didapatkan bahwa hampir sebagian responden pernah mengalami kekerasan dalam pacaran dari segi fisik. Bentuk kekerasan segi fisik yang paling banyak terjadi adalah menahan. Salah satu hal yang dapat menjadi pemicu kekerasan dalam pacaran segi fisik adalah pandangan remaja bahwa maskulinitas pria yaitu, agresivitas fisik. Pria secara fisik lebih kuat, namun bukan berarti boleh melakukan kekerasan. Hal ini sesuai dengan yang ter- tulis dalam kitab suci al-qur' an 'Wahai hamba-hamba-Ku, Aku haramkan kezaliman terhadap diri-Ku, dan Aku jadikan kezaliman itu juga haram di antara kamu, maka janganlah kamu saling menzalimi satu sama lain". (Hadis Qudsi, Riwayat Imam Muslim).

Berdasarkan penelitian didapatkan bahwa hampir sebagian responden pernah mengalami kekerasan dalam pacaran segi ekonomi. Kekerasan yang banyak terjadi adalah menggunakan uang dan barang pribadi tanpa pernah dikembalikan dan meminta dibelikan barang-barang. Kekerasan segi ekonomi tidaklah dapat dibenarkan, seperti yang kita dapatkan dalam nilai-nilai agama "tidak halal bagi kamu mempusakai perempuan dengan jalan paksa dan janganlah kamu menyusahkan mereka karena hendak mengambil kembali sebagian dari apa yang telah kamu berikan kepadanya, terkecuali bila mereka melakukan pekerjaan keji yang nyata".

Remaja putri usia 15-18 tahun pada umumnya belum memiliki penghasilan sendiri, meskipun demikian kekerasan dalam pacaran segi ekonomi masih saja dapat terjadi. Kekerasan ekonomi salah satunya terjadi karena adanya sikap materialistis dari pasangan.

\section{Kecenderungan Remaja Putri Menjadi Korban Kekerasan Dalam Pacaran}

Berdasarkan penelitian terdapat hampir sebagian responden memiliki kecenderungan menjadi korban kekerasan dalam pacaran. Kebanyakan dari remaja putri yang takut atau khawatir bahwa pacar mereka akan menyakiti atau melakukan balas dendam. Penyebab berlangsungnya kekerasan terus menerus adalah karena sikap pihak yang saling mendukung keberlangsungan kekerasan dalam hubungan mereka yaitu perempuan yang kelihatannya menerima kekerasan dalam berpacaran mengharapkan hubungan mereka berjalan dengan mulus, dan berharap pasangannya akan berubah pada akhirnya. Hal ini menjadi kecenderungan bahwa kekerasan dalam hubungan cinta pasangan pelajar sering dirahasiakan dan jarang dijadikan persoalan hukum. Akibatnya, kekerasan dalam pacaran menjadi fenomena terpendam yang berpotensi besar menghancurkan masa 
depan kaum putri (korban terbesar dari kekerasan dalam pacaran).

\section{Bentuk-Bentuk Kekerasan dalam Pacaran}

Penelitian ini juga menunjukkan bahwa responden yang memiliki kecenderungan menjadi korban kekerasan dalam pacaran paling banyak mengalami kekerasan segi seksual. Hal ini disebabkan harapan peran gender memainkan peranan penting dalam pembentukkan strategi remaja untuk mencocokkan diri dan agar mendapatkan penerimaan di lingkungannya terutama di masa awal remaja. Pria diharapkan untuk lebih mendominasi sedangkan wanita diharapkan untuk lebih pasif. Pria yang menganut peran gender yang mendominasi akan lebih cenderung mengesahkan perbuatan kekerasan dalam pacaran kepada pasangannya, sedangkan wanita yang menganut peran gender yang pasif, akan lebih menerima kekerasan dalam pacaran dari pasangannya.

\section{KESIMPULAN}

Kekerasan dalam pacaran segi emosional dialami sebagian besar responden $(56,3 \%)$. Kekerasan dalam pacaran segi seksual dialami sebagian kecil responden $(23,4 \%)$. Kekerasan dalam pacaran segi fisik dialami hampir sebagian responden $(39,2 \%)$. Kekerasan dalam pacaran segi ekonomi dialami hampir sebagian responden $(29,7 \%)$. Hampir sebagian responden memiliki kecenderungan menjadi korban kekerasan dalam pacaran (43\%). Bentuk kekerasan yang paling banyak dialami oleh remaja yang memi-

\section{DAFTAR RUJUKAN}

Adisti, P. 2010. Personality Plus for Teens. Jakarta: Pustaka Grhatama

American Bar Association. 2006. Teen Dating Violence Facts. USA: Author. Diperoleh dari: http://www.abanet.org/unmet/teendating/facts. pdf diakses tanggal 29 Januari 2012

Arifin, Nurul. 2003. Kekerasan dalam Pacaran. Diperoleh dari http://www.nurularifin.com diakses tanggal 29 Januari 2012

Arikunto, S. 2002. Prosedur Penelitian Suatu Pendekatan Praktek Edisi Revisi V. Jakarta : Rineka Cipta liki kecenderungan menjadi korban kekerasan dalam pacaran adalah kekerasan seksual $(30 \%)$.

Mengenai hal ini, kesimpulan yang dapat dibuat adalah masih tingginya angka kekerasan dalam pacaran pada remaja putri usia 15-18 tahun. Kekerasan dalam pacaran terjadi karena adanya ketimpangan kekuasaan antara laki-laki dan perempuan yang dianut oleh masyarakat luas. Ketidakadilan dalam hal jender selama ini telah terpatri dalam kehidupan sehari-hari, bahwa seorang perempuan biasa dianggap sebagai makhluk yang lemah, penurut, pasif, mengutamakan kepentingan laki-laki dan lain sebagainya, sehingga dirasa "pantas" menerima perlakuan yang tidak wajar atau semena-mena.

Remaja putri sesungguhnya harus memiliki kekuatan menolak kekerasan dalam bentuk apapun sehingga perempuanlah yang lebih mempunyai hak dan otonomi atas dirinya sendiri dan tahu apa yang lebih baik baginya. Perempuan bukanlah korban, melainkan kaum yang menjaga integritas dirinya sebagai manusia.

Dalam memberikan pelayanan kesehatan reproduksi kepada remaja diharapkan bekerja sama dengan guru dan orangtua. Diharapkan guru dan orang tua mau menjadi pendengar, memberi dukungan dan menjadi penolong bagi remaja yang ada dalam masalah ini. Guru dan orang tua diharapkan untuk terus mengawasi remaja dan pergaulannya untuk mengantisipasi terhadap berkembangnya perilaku ini.
Cornerstone pave program. 2005. What is Dating Violence? English: You have the right

Damanik, S.H.F. 2006. Menguak Makna Keperawanan Bagi Siswa Sekolah Menengah Atas. Jurnal Harmoni Sosial, Volume I, No. 1

Dianawati, A. 2010. From Single to Couple. Jakarta: GagasMedia

Family Prevention Fund. 2002. Preventing Family Violence. California: End Abuse 2009. The Facts on Teens and Dating Violence. USA: Author 
118 Jurnal Media Kesehatan, Volume 8 Nomor 2, Agustus 2014, hlm 100-204

Hurlock, E.B. 1999. Psikologi Perkembangan Suatu Pendekatan Sepanjang Rentang Kehidupan. Alih bahasa: Istiwidayanti. Jakarta: Erlangga

Kartono, K. 1989. Psikologi Abnormal dan Abnormalitas Seksual. Bandung: CV. Mandar Maju

2006. Psikologi Perkembangan Anak Gadis dan Wanita Dewasa. Bandung: CV. Mandar Maju

Kompas. 07 Maret, 2011. Komnas Catat 1.299 Kasus Kekerasan dalam Pacaran Sepanjang 2010.

. 19 November, 2007. Kekerasan Emosional Dalam Pacaran, Diam-Diam Mematikan.

Notoatmodjo, S. 2005. Metodologi Penelitian Kesehatan. Jakarta : Rineka Cipta.

NS, Sallika. 2010. Serba-serbi Kesehatan Perempuan. Jakarta: Bukunē

Powers, J. \& Kerman, E. 2006. Teen Dating Violence. New York: Univercity Of Rochester, and The New York State Centre For School Safety

Rahmawati, S .2008. Gambaran Kekerasan dalam Pacaran pada Remaja Putri Usia 17-21 Tahun di Program studi Kebidanan Kediri, Malang : Poltekkes Depkes Malang

Riwidikdo,H. 2010. Statistik Untuk Penelitian Kesehatan. Yogyakarta: Pustaka Rihima.
Santrock, J.W. 2003. Adolescence Perkembangan Remaja. Jakarta: Erlangga

Sarwono, S.W. 2010. Psikologi Remaja. Jakarta: PT RajaGravindo Persada

Set, S. 2008. Indonesia Anti Dating Violence. Jakarta: JBDK diperoleh dari: Http: www.Indonesia/Anti/Dating/Violence/Blog.ht ml.pdf diakses tanggal 29 Januari 2012

2009. Teen Dating Violence. Yogyakarta:Kanisius

Siagian, O. 2010. Gambaran bentuk-bentuk dating violence pada remaja yang berpacaran di Kota Medan. Medan: Universitas Sumatera Utara

Sitorus, M. 2006. Menjamin Hak Perempuan dan Anak Melalui Konvensi. Jakarta: Yayasan Jurnal Perempuan

Soetjiningsih. 2004. Tumbuh Kembang Remaja dan Permasalahannya. Jakarta : CV Sagung Seto

Soka Handinah Kacasungkana. 2005. Memutus Rantai Kekerasan Terhadap Perempuan. Surabaya : Lutfansah.

Straus, A.M. 2004. Prevalence of Violence Against Dating Partners by Male and Female. Journal of violence against woman (online). Diperoleh dari

FTP:

http://pubpages.unh.edu/ mas2/ID16.pdf: diakses tanggal 29 Januari 2012 